\section{A cable-swivel device for delivering shock to tail or harness electrodes}

\author{
CHRISTOPHER L. CUNNINGHAM \\ Yale University, New Haven, Connecticut 06520
}

An inexpensive cable-swivel device for delivering shock to tail or harness electrodes is described.

The advantages of being able to apply electric shock via tail or harness electrodes (Azrin, 1959; Rubin \& Brown, 1972; Weiss, 1967) are often overshadowed by an inability to deal efficiently, yet economically, with the problem of wires twisted by freely moving animals. Commercial devices that might solve this problem are usually designed for such sophisticated applications as bioelectric recording (e.g., BRS/LVE's electrocannular slip rings) and possess features that are not only unnecessary for shock delivery, but probably place the cost of such devices beyond the means of many equipment budgets. A number of homemade devices have been offered as alternatives (Ball \& Desiderato, 1972; Dixon, de Toledo, \& Black, 1969; Johnson, Trehub, \& Pietskowski, 1966), and although they solve the cost problem, they may present additional obstacles in terms of time and a need for machine-shop tools and skills. This note describes a very simple and inexpensive solution to these problems. The parts were obtained locally (at a hardware store and an electronics supply house) at a total cost under $\$ 3$. The only special purpose tool needed was an electric hand drill, and total assembly time was less than $10 \mathrm{~min}$.

The device is shown in Figure 1; its operating principle is straightforward. A standard two-pin phone plug is inserted through a nickel-plated brass panel bearing (H. H. Smith, Inc., Number 119) mounted in the (nonconductive) ceiling of the chamber and is held loosely in place with a shaft lock (H. H. Smith Inc., Number 181). Although the shaft lock appears to short-circuit the phone plug in the diagram, the plug actually comes in contact with the lock only beneath the tightening nut at its lower end. Thus, the wire (Lead B) looped around the panel bearing is connected electrically to just one of the plug's pins. The tip of the

The author was supported by a postdoctoral research fellowship from the National Institute of Mental Health (1 F32 MH05106-01). His present address is Department of Medical Psychology, University of Oregon Health Sciences Center, Portland, Oregon 97201.

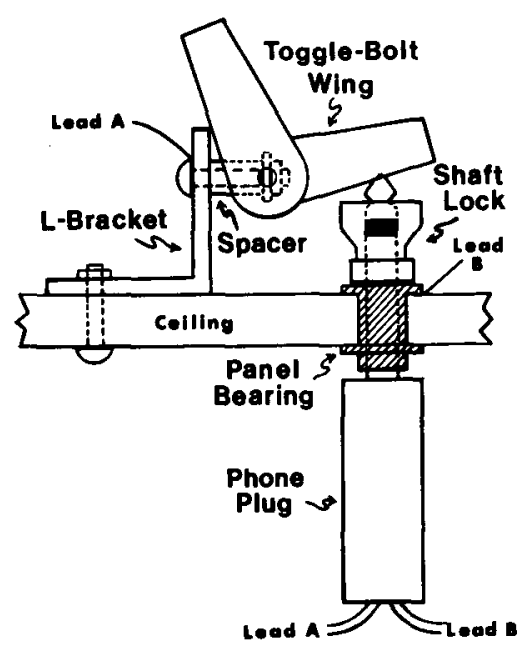

Figure 1. A cable-swivel device for delivering shock to tail or harness electrodes.

plug rests in a small indentation drilled on the surface of the "wing" from a spring-action toggle bolt. The wing is attached to a $1 \cdot \mathrm{in} .(2.54-\mathrm{cm}) \mathrm{L}$ bracket such that the spring exerts pressure downward on the plug, not only insuring contact between the wing and plug tip, but also between the shaft lock and panel bearing.

Despite the friction inherent in the system, the plug turns quite readily. I have been using four of these devices to deliver brief shock to pigeons keypecking on VI schedules for several months without problem.

\section{REFERENCES}

Azrin, N. H. A technique for delivering shock to pigeons. Journal of the Experimental Analysis of Behavior, 1959, 2. 161-164.

Ball, F. M., \& Desiderato, O. An inexpensive dual lead slip-ring for use with tail-shock electrodes. Journal of the Experimental Analysis of Behavior, 1972, 18, 179-180.

Dixon, C., DE Toledo, L., \& BlACK, A. H. A technique for recording electro-myographic activity in freely-moving rats using an all-purpose slip ring commutator. Journal of the Experimental Analysis of Behavior, 1969, 12, 507-509.

Johnson, R. N., Trehub, A., \& Pietskowsk, E. An easilyconstructed cable swivel device for brain stimulation experiments. Journal of the Experimental Analysis of Behavior, 1966, 9, 17-18.

Rubin, H. B., \& Brown, H. J. A harness and electrode connector for rats. Joumal of the Experimental Analysis of Behavior, 1972, 18, 385-388.

WEISS, J. M. A tail electrode for unrestrained rats. Journal of the Experimental Analysis of Behavior, 1967, 10, 85-86.

(Received for publication December 9, 1977; accepted December 16, 1977.) 